\title{
Economic Integration in the Quality Ladder Model
}

\author{
- Eduardo Correia de Souza*
}

\begin{abstract}
RESUMO
Realizamos aqui o mesmo tipo de "experimentos de integração" que em Rivera-Batiz e Romer (I99I), desta vez no contexto de um modelo de "escada de qualidade", onde integração via comércio internacional não é suficiente para impedir redundância de esforços de $P \& D$. Daí que um tipo adicional de integração seja analisada: "integração financeira". Adotamos como arcabouço o "modelo Schumpeteriano Simples" de Aghion e Howitt (2005), cuja tecnologia de inovação difere claramente daquelas concebidas em RiveraBatiz e Romer (I99I) por exibir retornos decrescentes de escala.
\end{abstract}

\section{Palavras-Chave}

crescimento endógeno, integração econômica internacional, inovação

\section{ABSTRACT}

Here we perform the same kind of "integration experiments" as in Rivera-Batiz and Romer (I99I), this time in the context of a "quality ladder model", where international trade integration is not enough to prevent redundancy of $R \& D$ efforts. Thus a further kind of integration is analysed: "financial market integration". We adopt as a setup the Simple Schumpeterian Model in Aghion and Howitt (2005), whose innovation technology differs sharply from the ones conceived by Rivera-Batiz and Romer in that it displays decreasing returns to scale.

\section{KEYWORDS}

endogenous growth, international economic integration, innovation

JEL CLASSIFICATION

$033,034,016, F 15$

* IBMEC São Paulo. Address: Rua Quatá, 300 - Vila Olímpia - São Paulo - SP - Brazil - CEP: 04546-042. E-mail: eduardocs@isp.edu.br.

(Recebido em novembro de 2005. Aceito para publicação em junho de 2007). 


\section{INTRODUCTION}

Here we perform the same kind of "integration experiments" as in Rivera-Batiz and Romer (1991), this time in the context of a "quality ladder" endogenous growth model. In that latter paper, based on a "variety expansion" endogenous growth model, ${ }^{1}$ flows of goods or flows of ideas (depending on the specification of research technology) between countries was all that was required to promote an increase in the long run world growth rate, thus taking advantage of increasing returns to scale displayed by the reduced form production functions of designs for new products. The problem of redundancy or duplication of $\mathrm{R} \& \mathrm{D}$ efforts was naturally circumvented by a kind of "axiom of choice" underlying the rationality of innovators: there exists complete information in the sense that potential innovators know, previously from their having come into being, all the possible varieties of goods, so that they can choose which one they are going to try to innovate and avoid choosing the same that another innovator is targeting. As Rivera-Batiz and Romer (1991) put it:

In the pursuit of monopoly rents, researchers in the two countries will specialize in the production of different types of designs and avoid redundancy, so the worldwide stock of designs will ultimately be twice as large as the stock that has been produced in either country. ${ }^{2}$

This presumption cannot be expected to apply to a quality-ladder model, where the set of goods targeted to be innovated is bounded. In our setup the coordination required to prevent duplication can only be brought about by what we call "financial market integration": research activity is financed not by retained profits at firms' level but by individuals' savings in exchange for shares of potential monopolist firms; although it is not possible to prevent Bertrand competition driving profits to zero after simultaneous innovations happen, the financial market is capable of supporting/implementing any number of potential innovators per good so as to maximize the total return to shares. Thus, for example with the probability that a simultaneous innovation occurs when independent researchers aim the same good being given by the product of the individual probabilities, then it will never be the case that in an integrated capital market more than one firm receives resources to innovate on a given good when R\&D technology (whose output is a probability of innovating) displays constant or increasing returns to scale.

1 Grossman and Helpman (1991) introduced the terminology "quality ladder" as opposed to "variety expansion" endogenous growth models. In the first case a bounded, constant measure set of goods are quality improved through innovation; in the second case, the set of goods is expanded through innovation.

2 Rivera-Batiz and Romer (1991, p. 543). 
Still, as long as capital is not internationally mobile and investment in each country is uniformly widespread through the usual unitary measure or finite set of goods, there will always remain two firms bound to simultaneously innovate. Although this latter is a central feature of our present model, the particular phenomenon of duplication of R\&D efforts analysed here will emerge as a result of the interaction of other factors such as the "free flows of ideas" and the regime of Intellectual Property Rights.

Because of the very assumption that one country will always be an integrated financial market, we cannot speak here of "atomistic agents" for whom there are (as if) constant returns to $\mathrm{R} \& \mathrm{D}$ while there are actually diminishing returns from a social standpoint, as is the case in Jones and Williams (1999). Accordingly, we incorporate the fortuitous event of duplication in the innovators' maximization problem, what may in some cases revert the tendency of "patent races" to generate overinvestment.

The setup we choose to work with is Aghion and Howitt (2005) handbook's. It proves not only easy to handle for our purposes, as it generates some ambiguous results not found in Rivera-Batiz and Romer (1991). For example, because of internationally different levels of protection to Intellectual Property, there is no guarantee that this particular lab equipment specification of $R \& D$ technology $y^{3}$ will generate a positive growth effect under trade integration. Thanks to the simple functional forms adopted by Aghion and Howitt (2005) in their handbook's Schumpeterian model, it will be in general possible to predict when one effect of integration (say, trade enabling producers to take advantage of increasing returns to innovation, the "market size effect") will outweigh the other effect (say, increased competition with competitive fringes worldwide).

Now, several people have already used endogenous growth models, or more specifically the quality ladder model, in an international context to investigate integrationrelated problems. Gancia (2003) used a quality ladder model whose final goods present gross substitutability and assumed that the South (or developing countries' block) provides weaker IPRs protection to study how trade integration promotes "innovation diversion" and "stagnation" effects: With international financial capital or knowledge mobility existing prior to trade, each country produces the whole range of goods and therefore innovators, serving the world economy, obtain both the high rents from the North and the low rents from the South independent from

3 Rivera-Batiz and Romer (1991) call "lab equipment R\&D technology" one in which R\&D uses the same inputs as the final good's production, or directly the final good as the only input. As opposed to this, they call "knowledge-driven R\&D technology" one in which the inputs are the stock of knowledge and human capital, while in the production of final good what is used is capital and/or unskilled labour. In this latter case, the analysis has to be carried through a two sectors' model. 
the good they target. Under free trade, instead, the North and South blocks specialize according to comparative advantages and returns to innovation will depend on which good is targeted, so that technical change is shifted in favor of Northern countries, raising their productivity and making them relatively richer. But as relative wages (North/South) raise, comparative advantage is continually displaced to the South, so more and more sectors move to the South where IPRs protection and returns to $\mathrm{R} \& \mathrm{D}$ are smaller, thereby eroding global incentives to innovation.

Taylor (1994) studied the impact of a change from symmetric to asymmetric IPRs protection on the global rate of growth, so that unlike Gancia (2003) he was dealing with the general problem of (absence of) international financial capital mobility instead of focusing on North-South differences. To Taylor, asymmetric protection meant not only that R\&D and production of a certain good have to be performed in the same country/location, but also that patents are granted/recognized in a certain country inasmuch who applies for them are domestic firms. (And this same regime holds in the home country and in the rest of the world alike). Therefore, his picture of asymmetric protection amounts to exactly the same thing as our case of international trade in the absence of financial integration.

Finally, Aghion and Howitt (2005) use their basic framework, which we adopt here, to study convergence clubs, that is, why some countries tend to display a common positive productivity growth rate in the long run while others will stagnate. To do this, they follow Howitt's (2000) model with intersectoral as well as international knowledge spillovers. Intersectoral spillovers simply imply that we may work as with an aggregate (one sector) model. The international spillover or technology transfer, as Aghion and Howitt (2005) put it, "allows a backward sector in one country to catch up with the current technological frontier whenever it innovates. The further behind the frontier a country is initially, the bigger the average size of its innovations, and therefore the higher its growth rate for a given frequency of innovations. As long as the country continues to innovate [with some positive frequency], no matter how small, it will eventually grow at the same rate as the leading countries. (Otherwise the gap would continue to rise and therefore the country's growth rate would continue to rise). However, countries with poor macroeconomic conditions, legal environment, educational system or credit markets will not innovate in equilibrium and therefore they will not benefit from technology transfer, but will instead stagnate."4

So why our paper? In the first place, both Taylor (1994) and Gancia (2003) used Ricardian Comparative Advantage models, which naturally rules out the possibility of international duplication of R\&D efforts. In Taylor, what we call here "financial

4 Aghion and Howitt $(2005$, p. 9). 
integration" amounts only to render the best R\&D technology available to innovators worldwide. Here we also have this same effect, but "financial integration" further stands out as the level of integration (beyond knowledge spillovers and trade) required to prevent duplication. Second, with relation to international knowledge spillovers, our conception is different from Howitt's (2000). There, the free international flow of ideas makes the technology frontier available to potential innovators, while here it becomes available to final good producers directly. Last but not least, we think our work differs from the above mentioned international economy applications of the quality ladder model in that it bears the same spirit of RiveraBatiz and Romer's (1991) integration experiments: it is a step-by-step integration analysis, where we first have international knowledge spillovers but not trade nor financial (capital mobility) integration; then we investigate what changes when we add trade to the picture but yet without financial integration, and so on. We think it is worth while repeating Rivera-Batiz and Romer's (1991) integration experiments this time using Aghion and Howitt's (2005) model among other things because this last setup's innovation technology differs sharply from the ones conceived by Rivera-Batiz and Romer in that it displays decreasing returns to scale.

A last word of warning: although it will be impossible not to deal with "distortions" (wedges between private and social returns to innovation) such as the one at the root of the so called "creative destruction effect", our concern here is only with the "mechanism" of integration, not with welfare properties of the model or how (much) integration may per se eliminate or attenuate distortions ${ }^{5}$. The next section presents Aghion and Howitt's (2005) simple Schumpeterian model, whose outcome is the steady state growth rate for an autarky; the subsequent sections add up further levels of international economic integration.

\section{THE BASIC SETUP: AGHION AND HOWITT'S (2005) SIMPLE SCHUMPE- TERIAN MODEL ${ }^{6}$}

There are two kinds of goods in the economy: a final good and $m$ different intermediate inputs. The only production factor is (skilled) labour. Time is discrete, indexed by $t=1,2, \ldots$, and there is a mass $L$ of individuals, each endowed with one unit of skilled labor that she supplies inelastically. The final good is produced competitively using the intermediate inputs and labor, according to the production function:

5 The reader interested on those welfare aspects of innovation, especially distortions under "patent races" should consult Dasgupta and Maskin (1987) and Stokey (1995).

6 This section merely reproduces, with a few minor changes, Aghion and Howitt's (2005, section 2.2) text. 


$$
y_{t}=\left(\sum_{i=1}^{m} A_{i t}^{1-\alpha} \cdot x_{i t}^{\alpha}\right) \cdot\left(\frac{L}{m}\right)^{1-\alpha}
$$

where each $x_{i t}$ is the flow of intermediate input $i$ used at date $t$, and $A_{i t}$ is a productivity variable that measures the quality of the input. The final good is used in turn for consumption, research, and producing the intermediate inputs.

The economy's average growth rate $g$ will be the expected growth rate of any given productivity variable. Measuring discrete-time growth rates as log differences, we have:

$$
g=E\left(\ln A_{i t}-\ln A_{i, t-1}\right) \equiv E \Delta \ln A_{i t}
$$

Accordingly we focus now on one representative intermediate sector, eliminating the $i$ subscript for notational simplicity. ${ }^{7}$

Innovations result in improved versions of the intermediate input. More precisely, each innovation at $t$ multiplies the pre-existing productivity parameter $A_{t-1}$ of the best available input by a factor $\gamma>1$. Innovations in turn result from research. If $N_{t}$ units of the final good are invested at the beginning of the period, some individual can become the new "leading-edge" producer of the intermediate input with probability

$$
\lambda \cdot f\left(n_{t}\right), \quad f^{\prime}>0, \quad f^{\prime \prime}<0, \quad f(0)=0
$$

where $\lambda$ is a research productivity parameter and $n_{t} \equiv\left(N_{t} /\left(\gamma \cdot A_{t-1}\right)\right)$ is the productivityadjusted $\mathrm{R} \& \mathrm{D}$ expenditure in the sector. We divide by $\gamma \cdot A_{t-1}$, the targeted productivity parameter, to take into account the "fishing-out" effect - on average each quality improvement is harder to bring about than the previous one.

Assume the time period is short enough that we may ignore the possibility of more than one successful innovator in the same sector. Then:

$$
\ln A_{t}=\ln A_{t-1}+\ln \gamma \quad \text { with probability } \quad \lambda . f(n)
$$

7 That being so, the reader may wonder why we use a functional form with $\mathrm{m}$ intermediate goods in expression (1) above. The reason is simply that we adopt Aghion and Howitt's (2005) framework, which originally was intended to be quite general and comprehensive - for example, it gives room to analysing trade in intermediate goods and innovation in a "variety expansion" fashion (with $\mathrm{m}$ growing over time), none of which are studied here. 


$$
\ln A_{t-1} \quad \text { with probability } \quad 1-\lambda . f(n)
$$

According to (2) and (4) the average growth rate is:

$$
g=\lambda \cdot f(n) \cdot \ln \gamma
$$

in an equilibrium where productivity-adjusted research is a constant $n$. The growth rate, therefore, results from $\lambda . f(n)$, representing the frequency of innovation, and $\ln \gamma$, representing the incremental size of innovations.

The model determines research $n$, and therefore the growth rate $g$, using a research arbitrage equation that equates the expected cost and benefit of research. The payoff to research is the prospect of a monopoly rent $\pi_{t}$ if the research succeeds in producing an innovation. This rent lasts for one period only, as all individuals can imitate the current technology next period. Hence the expected benefit from spending one unit on research is the marginal probability $\lambda \cdot f^{\prime}(n) /\left(\gamma A_{t-1}\right)$ times $\pi_{t}$. Taking the final good as numeraire, the research arbitrage condition becomes

$$
1=\lambda \cdot f^{\prime}(n) \cdot\left(\pi_{t} / A_{t}\right)
$$

To solve this equation for $n$ we need to determine the productivity-adjusted monopoly rent $\pi_{t} / A_{t}$ to a successful innovator. This innovator can produce the leadingedge intermediate input at a constant marginal cost of one unit of the final good. But she faces a competitive fringe of imitators who can produce the same input at a constant marginal cost $\chi$, where $\chi \in\left(1, \frac{1}{\alpha}\right)$. The parameter $\chi$ is an inverse measure of the degree of product market competition or imitation in the economy. ${ }^{8}$ The innovator is forced to charge a limit price (in terms of the final good, our numeraire) equal to:

$$
p_{t}=\chi
$$

to prevent the fringe from stealing her market. Hence the monopoly rent is:

$$
\pi_{t}=\left(p_{t}-1\right) \cdot x_{t}=(\chi-1) \cdot x_{t}
$$

Because the final-good producing sector is competitive, $x_{t}$ is determined by the marginal productivity condition:

8 If no innovation succeeds then some firm will produce domestically but with no cost advantage over the fringe because everyone is able to produce last period's intermediate input at a constant marginal cost of unity. Therefore, profits due to innovation last only one period. 


$$
p_{t}=\chi=\partial y_{t} / \partial x_{t}=\alpha\left(m x_{t} / A_{t} L\right)^{\alpha-1}
$$

That is, the monopolist's output $x_{t}$ is the amount of intermediate good demanded by firms in the final good sector when they are faced with the price $\chi$. So (8) simply states that $x_{t}$ must be such that the marginal product of the intermediate good equates its price.

Solving (8) for $x_{t}$ and substituting in (7):

$$
\pi_{t}=\delta(\chi) A_{t} L / m
$$

where

$$
\delta(\chi) \equiv(\chi-1) \cdot(\chi / \alpha)^{1 /(\alpha-1)}, \quad \delta^{\prime}(\chi)>0
$$

Thus we can write the research arbitrage equation (6), taking into account that $\gamma \cdot A_{t-1}=A_{t}$ because a monopolist is someone who has just innovated, as:

$$
1=\lambda \cdot f^{\prime}(n) \cdot(\chi-1) \cdot(\chi / \alpha)^{1 /(\alpha-1)} \cdot L / m
$$

which we assume to have a single positive solution for $n$. If the research-productivity function $f$ takes the simple form: $f(n)=\sqrt{2 n}$, then

$$
n=\lambda^{2} \cdot \frac{1}{2} \cdot(\chi-1)^{2} \cdot\left(\frac{\chi}{\alpha}\right)^{\frac{2}{\alpha-1}} \cdot\left(\frac{L}{m}\right)^{2}
$$

The average growth rate is determined by substituting (1l') into the growth equation (5) :

$$
g=\lambda \sqrt{2 n} \ln \gamma=\lambda^{2}(\chi-1)(\chi / \alpha)^{1 /(\alpha-1)}(L / m) \ln \gamma
$$

Aghion and Howitt (2005) show that (12) is not only the average growth rate of each intermediate good sector's productivity parameter, but also approximately the growth rate of the economy's per capita GDP.

\section{Comparative Statics on Growth}

Equation (12) delivers several comparative statics results, each with important policy implications on how to "manage" the growth process: 
Growth increases with the productivity of innovations $\lambda$ and with the supply of skilled labor $L$ : both results point to the importance of education and particularly higher education as a growth-enhancing device. Indeed countries that invest more in higher education will both achieve a higher productivity of research activities and also reduce the (opportunity) cost of $\mathrm{R} \& \mathrm{D}$ by increasing the aggregate supply of skilled labor. An increase in the size of population should also bring about an increase in growth by raising $L$. This result amounts to the famous "scale effect" criticised by Jones (1995).

Growth increases with the size of innovations, as measured by $\gamma$. This in turn points to the existence of a wedge between private and social innovation incentives: if given the choice between increasing the frequency $\lambda$ or increasing their size $\gamma$, the private individual will go for increasing frequency as size does not affect the expected returns to R\&D as expressed on the right side of equation (11); however, equation (12) shows that small innovations, with $\gamma$ close to one, will result in slow growth. This is an instance of the so-called "creative destruction effect": each new innovator builds on the previous innovator's result, but all she cares about is the monopoly power resulting from quality differentiation, not at all how big the quality improvement was. Other things constant, this leads to decentralised (market) equilibrium over-investment in R\&D.

Growth is decreasing with the degree of product market competition and/or with the degree of imitation as inversely measured by $\chi$. Thus patent protection (or, more generally, better protection of intellectual property rights), will enhance growth by increasing $\chi$ and therefore potential rewards from innovation. Conversely, a competition policy will tend to discourage innovation and growth by reducing $\chi$ and thereby forcing incumbent innovators to charge a lower limit price. ${ }^{9}$

\section{INTEGRATION AS FREE FLOW OF IDEAS}

\subsection{Knowledge Spillovers, IPRs and Simultaneous Innovations}

Building on Aghion and Howitt (2005) handbook's simple Schumpeterian growth model, we first consider a world with potentially free flows of ideas, no trade in goods and symmetric as to access but internationally different levels of Intellectual

9 This feature of the first generation Schumpeterian endogenous growth models is subject to qualification. As Aghion and Howitt (2005, p.8) put it, "Existing historical evidence supports the view that property rights protection is important for sustained long-run growth; however the prediction that competition should be unambiguously bad for innovations and growth is questioned by all recent empirical studies..." 
Property Rights. Consider first the case where IPRs are not product-patent like; instead, they work as a system of prohibition claims: whenever and wherever an innovation happens, it instantaneously becomes common knowledge in any country if the innovator does not recur to that country's IPRs system, which then (and only then) imposes a certain cost on potential imitators for one period only. Without the possibility of licensing and without trade in goods, home country's innovators have no claims on profits earned by imitators abroad, so they will recur only to local IPRs protection. Since new knowledge is then free abroad, foreign imitators engage in Bertrand's competition driving prices to average/marginal cost. This latter cost is assumed to be identical to the cost faced by innovators, being given, say, by technology; what amounts to say that mark-ups or limiting prices against the fringes of imitators ( $\chi_{s}$ below) are solely determined by the extent of IPRs protection in each country.

In such a framework, when a simultaneous innovation occurs in two different countries, each country's imitators are free to copy from abroad, ${ }^{10}$ causing the local innovators a total loss. This takes for granted a non cooperative behaviour on the part of innovators, what is a reasonable assumption as long as we suppose that financial innovative capital is not internationally mobile. As a result, at any period there will be two production levels of intermediate goods: if they were innovated only at home, they are priced according to a non-competitive mark-up; otherwise they are competitively priced and supplied.

In this world, not only innovations performed anywhere add to the world's technological frontier, as they are always instantaneously and one by one absorbed or made available to local final good producers. So there is no "catching-up story" like in Aghion and Howitt's (2005) section 3.1 on "technology transfer": In this latter paper, as well as in Howitt's (2000) original setup, international knowledge spillovers are "indirect" in that they accrue first to potential innovators, not to final good producers. At time $t$ in a given country, if no innovation occurred, final good producers have to fare with that country's "low" old productivity level $\mathrm{A}_{j, t-1}$ in intermediate $\operatorname{good} j$, a productivity level that may be very far from the world technology frontier $\overline{A_{j, t-1}}$. However, it is on that $\overline{A_{j, t-1}}$ world frontier basis that local innovators work to improve on, so that in case the innovation at time $t$ is successful this country jumps the whole distance $\bar{A}_{j, t-1}-A_{j, t-1}$ as an externality, plus the one-step-size current improvement. ${ }^{11}$

10 For they (imitators) can sustain they are drawing the relevant information from the foreign innovator, who has made no prohibitionist claim against disclosing his "secret" in the home country's IPR system.

11 Yet, reading section 2 above, we realise that Aghion and Howitt (2005) adopt also a knowledge spillover to final good producers at national level when they assume that after one period the state-of-the-art 
Finally, we are explicitly doing away with last section's assumption that the time period is short enough so that we can ignore the possibility of more than one successful innovator in the same sector. Actually, what we are considering is a situation such that, from the point of view not necessarily of the technological discoveries themselves, but of the economically relevant accruing of extraordinary profits through IPRs protection, it is as if simultaneous innovations occurred. La Manna, Macleod and Meza (1989) argue that, as matter of fact, something like that is already in course in many countries, including the US Patent and Trademark Office, which are adopting the "secrecy period" procedure, by which from the time of the first application for a given patent until its judgement/publication more applicants are allowed to enter the process, with the provision that during this period technical details of the submitted applications are kept secret. This system gives origin not necessarily to monopolies only, but possibly to oligopolies too and, in our framework, to Bertrand competition driving profits to zero.

\subsection{The Simple Schumpeterian Model with Duplication}

If $N_{t}$ units of the final good are invested at the beginning of period $t$, the home country's potential innovator can become the new "leading-edge" producer of the intermediate input with probability

$$
\mu_{t D} \lambda \cdot f\left(n_{t}\right)-\lambda \cdot f\left(n_{t}\right) \cdot \lambda^{*} \cdot f\left(n_{t}^{*}\right)
$$

That is, the probability that he innovates minus the probability of a simultaneous innovation under independent innovative efforts. If a simultaneous innovation occurs, his profits are driven to zero and production is carried out by home country's imitators of the foreign identical technology. Expression (13) takes for granted that in running many small innovative firms the loss due to duplication "outweighs" the gain from exploring decreasing returns in individual firm's technologies to the point that, in each national integrated capital market such as defined in section 1 , it is optimal to run only one R\&D project for each intermediate good. ${ }^{12}$ Since we do not yet assume trade in intermediate goods, the research arbitrage conditions involve, for each innovator, only profits earned in domestic markets:

intermediate good can be imitated.

12 For more details on that issue, see the beginning of section 5 below. At this point we observe that the existence of only one firm as potential innovator in each country doesn't exclude free entry. One may think of free entry in our "integrated financial market" in the following terms: if for the marginal unit of final good allocated to R\&D the expected value of a firm is bigger than the cost of innovation, then the financial market is not able to prevent side independent investment; but that would on its turn drive firms' values below the cost of innovation. 


$$
\left\{\begin{array}{l}
1=\lambda \cdot \frac{f^{\prime}\left(n_{t}\right)}{\gamma \cdot A_{t-1}} \cdot\left[1-\lambda * \cdot f\left(n_{t}^{*}\right)\right] \cdot \pi_{t} \\
\text { and } \\
1=\lambda * \cdot \frac{f^{\prime}\left(n_{t}^{*}\right)}{\gamma \cdot A^{*}{ }_{t-1}^{*}} \cdot\left[1-\lambda \cdot f\left(n_{t}\right)\right] \cdot \pi_{t}^{*}
\end{array}\right.
$$

analogous to (6) above

With

$$
\pi_{t}=\delta(\chi) \cdot A_{t} \cdot \frac{L}{m} \quad \text { and } \quad \pi_{t}^{*}=\delta\left(\chi^{*}\right) \cdot A_{t} * \frac{L^{*}}{m}
$$

Substituting (15) in (14), adopting the functional form $f(n)=\sqrt{2 \cdot n}$ and solving for $n$, comes

$$
n_{D}=\varepsilon_{D} \cdot \lambda^{2} \cdot \frac{1}{2} \cdot(\chi-1)^{2} \cdot\left(\frac{\chi}{\alpha}\right)^{\frac{2}{\alpha-1}} \cdot\left(\frac{L}{m}\right)^{2}=\varepsilon_{D} \cdot n
$$

where the subscript $D$ stands for "duplication" and $n$ on the right side of the second equality is the productivity adjusted R\&D expenditure under complete isolation, defined in section 2 above, expression (11'). As to the term $\varepsilon_{D}$,

$$
\varepsilon_{D}=1-2 \cdot \lambda^{*} \cdot\left[\lambda^{*} \cdot\left(1-\lambda \cdot \sqrt{2 n_{D}}\right)\left(\chi^{*}-1\right) \cdot\left(\frac{\chi^{*}}{\alpha}\right)^{\frac{1}{\alpha-1}} \cdot\left(\frac{L^{*}}{m}\right)\right]+\lambda^{* 2} \cdot[\bullet]^{2}
$$

or

$$
\varepsilon_{D}=(1-\lambda * \cdot[\bullet])^{2}<1
$$

since $\left(1-\lambda^{*} \cdot[\bullet]\right)=1-\lambda^{*} \cdot f\left(n_{D}^{*}\right)$, the probability that an innovation does not occur abroad. Thus $n_{D}<n$ : In the absence of market extension gains from trade integration, and with free flows of information bringing about the possibility of a total loss whenever duplication occurs, each innovator will allocate less resources to $\mathrm{R} \& \mathrm{D}$ if compared to the former complete isolation situation. To calculate the rate of growth under "duplication", $g_{D}$, first notice that under the assumptions regarding

13 An entirely analogous expression holds for the rest of the world $\left({ }^{*}\right)$. 
knowledge spillovers we made, every country will be growing at this same rate. Then,

$\ln \max \left(A_{t}, A_{t}^{*}\right)=\left\{\begin{array}{l}\ln \max \left(A_{t-1}, A_{t-1} *\right)+\ln \gamma, \text { with probab. } \\ \mu_{\mathrm{D}} \equiv \lambda \cdot f\left(n_{D}\right)+\lambda^{*} \cdot f\left(n_{D} *\right)-\lambda \cdot f\left(n_{D}\right) \cdot \lambda^{*} \cdot f\left(n_{D} *\right) \\ \ln \max \left(A_{t-1}, A_{t-1} *\right), \quad \text { with probab. } 1-\mu_{D}\end{array}\right.$

where $\mu_{D}$ is the probability that an innovation happens either in the home country ( ) or abroad $(*)$.

Then

$$
g_{D} \equiv E\left(\ln \max \left(A_{t}, A_{t}^{*}\right)\right)-\ln \max \left(A_{t-1}, A_{t-1}^{*}\right)=\mu_{D} \cdot \ln \gamma
$$

Under $f(n)=\sqrt{2 \cdot n}$ and by $(16)$

$$
g_{D}=\left(\lambda \cdot \sqrt{\varepsilon_{D}} \cdot \sqrt{2 n}+\lambda * \sqrt{\varepsilon_{D}^{*}} \cdot \sqrt{2 n^{*}}-\lambda \cdot \lambda * \cdot \sqrt{\varepsilon_{D} \cdot \varepsilon_{D}^{*}} \cdot \sqrt{n \cdot n^{*}} \cdot 2\right) \cdot \ln \gamma
$$

Given this expression, comparing to $g$ (the home country's growth rate at isolation) in section 2, expression (12) above, a first question arises: which is the prevailing effect on the rate of growth: the positive effect due to the free flow of ideas (knowledge spillovers) or the negative effect via the reduced allocation of resources to $\mathrm{R} \& \mathrm{D}$ in face of duplication?

Calling for notational simplicity $p$ and $p^{*}$ the probabilities that each country innovates (a discovery is made) under "isolation", and $p_{D}$ and $p_{D}^{*}$ the same for "duplication", so that $p_{D}=p \cdot \sqrt{\varepsilon_{D}}$, we have

$$
g_{D}>g \Leftrightarrow \mu_{D}>p \Leftrightarrow p \cdot \sqrt{\varepsilon_{D}}+p^{*} \cdot \sqrt{\varepsilon_{D}{ }^{*}}-p \cdot \sqrt{\varepsilon_{D}} \cdot p^{*} \cdot \sqrt{\varepsilon_{D}^{*}}>p
$$

Next, recalling that $\sqrt{\varepsilon_{D}}=1-p_{D}^{*}>1-p^{*}$ since $n^{*}>n_{D}^{*}$, and alike for $\sqrt{\varepsilon_{D}^{*}}$, a sufficient condition for (20) to hold is 


$$
p^{*} \cdot(1-p)>\frac{p \cdot p^{*}}{1-p+p \cdot p^{*}}
$$

Ignoring third order and smaller terms in (21), a sufficient condition for (20) to hold is simply $p<\frac{1}{3}$. That is, irrespective how much the rest of the world innovates, whenever the home country does not innovate too much under isolation, the positive integration effect via free flow of ideas will prevail.

Under more standard patent protection and with no trade yet, never mind what innovators abroad do an innovator can guarantee that he will be, for one period, the only producer of the new generation of the intermediate good in his country's market. Therefore, the amounts $n$ and $n^{*}$ allocated to R\&D are the same as under isolation, expression (11') above, and the growth rate is given simply by

$$
g_{D P}=\left(\lambda \cdot \sqrt{2 n}+\lambda^{*} \cdot \sqrt{2 n^{*}}-\lambda \cdot \lambda^{*} \cdot \sqrt{n \cdot n^{*}} \cdot 2\right) \cdot \ln \gamma
$$

or, using the above notation for probabilities,

$$
g_{D P}=\left(p+p^{*}-p \cdot p^{*}\right) \cdot \ln \gamma>p \cdot \ln \gamma=g
$$

where the subscript $P$ stands for "patent protection". In this case the effect of "free flows of ideas" is unambiguously an increase in the growth rate: $g_{D P}>g$. Duplication supervenes simply as the overlapping in research efforts already existing when the two economies were isolated. Under "integration", each economy starts benefiting from what the other made of different.

The analogy with the variety-expansion, lab equipment specification of $R \& D$ model of Rivera-Batiz and Romer (1991, p. 549) is that as trade is responsible there for making all the worldwide existing types of capital equipment available to be used in all research activities undertaken anywhere, here knowledge spillovers guarantee that only worldwide ultimate generations of all the intermediate goods are used in final good's production everywhere, increasing the productivity of a given/fixed stock of labour allocated to it. ${ }^{14}$ However, we are far yet from the operation of an integrated research sector; actually, it is the very presence of knowledge spillovers that makes duplication, a kind of simultaneous redundancy in research, bound to happen. In Rivera-Batiz and Romer (1991) all that is needed to remove this latter inefficiency is trade in intermediate goods, what we incorporate next.

14 Recall expression (1) above. 


\section{INTEGRATION VIA TRADE IN INTERMEDIATE GOODS}

When a firm is the only in the world that has discovered how to produce the stateof-the-art of an intermediate good, it will earn profits equal to

$$
\pi_{G t}=\left(\chi_{\min }-1\right) \cdot\left(x_{t}+x_{t}^{*}\right)
$$

Where the subscript "G" stands for "global", $\chi_{\min }=\min \left(\chi, \chi^{*}\right)$ is the limit price it can charge when free and instantaneous flows of ideas enables imitation to be carried at the internationally minimal cost, ${ }^{15}$ and the terms $x$ and $x^{*}$ are the demands for the intermediate good given by the condition that its price be equal to its value marginal productivity, namely

$$
\begin{aligned}
& \chi_{\min }=\frac{\partial y_{t}}{\partial x_{t}}=\frac{\partial y_{t}^{*}}{\partial x_{t}^{*}} \Rightarrow x_{t}=\frac{L}{m} \cdot A_{t} \cdot \alpha^{\frac{1}{1-\alpha}} \cdot \chi_{\min }^{\frac{1}{\alpha-1}} \\
& \text { and } \quad x_{t}^{*}=\frac{L^{*}}{m} \cdot A_{t} \cdot \alpha^{\frac{1}{1-\alpha}} \cdot \chi_{\min }^{\frac{1}{\alpha-1}}
\end{aligned}
$$

where it is assumed, accordingly, $A_{t}=A_{t}^{*}$

So that, using (24) in (23),

$$
\pi_{G t}=\frac{L+L^{*}}{m} \cdot A_{t} \cdot \alpha^{\frac{1}{1-\alpha}} \cdot \chi_{\min }^{\frac{1}{\alpha-1}} \cdot\left(\chi_{\min }-1\right)
$$

The familiar research arbitrage conditions are, in this case,

$$
\left\{\begin{array}{l}
1=\lambda \cdot \frac{f^{\prime}\left(n_{t}\right)}{\gamma \cdot A_{t-1}} \cdot\left[1-\lambda^{*} \cdot f\left(n_{t}^{*}\right)\right] \cdot \pi_{G t} \\
\text { and } \\
1=\lambda^{*} \cdot \frac{f^{\prime}\left(n_{t}^{*}\right)}{\gamma \cdot A_{t-1}} \cdot\left[1-\lambda \cdot f\left(n_{t}\right)\right] \cdot \pi_{G t}
\end{array}\right.
$$

recalling that $A_{t}=A_{t-1} \cdot \gamma$

15 When trade takes place domestic firms decide to seek for foreign protection in order to avoid competition in the form of exports from imitators. 
Adopting again the functional form $f(n)=\sqrt{2 n}$, using (25) in (26), and then solving (26) for $n_{t}$, comes

$$
\begin{aligned}
& n_{T D}=\lambda^{2} \cdot \frac{1}{2} \cdot\left\{1-2 \cdot \lambda^{*} \cdot\left[\lambda^{*} \cdot\left(1-\lambda \cdot \sqrt{2 n_{T D}}\right)\left(\chi_{\min }-1\right) \cdot\left(\frac{\chi_{\min }}{\alpha}\right) \cdot \frac{L+L^{*}}{m}\right]+\lambda^{* 2} \cdot[\bullet]^{2}\right\} . \\
& \left(\chi_{\min }-1\right)^{2} \cdot\left(\frac{\chi_{\min }}{\alpha}\right)^{\frac{2}{\alpha-1}} \cdot\left(\frac{L+L^{*}}{m}\right)^{2}
\end{aligned}
$$

where the subscripts $T$ and $D$ stand respectively for "trade" and "duplication". Expression (27) can be rewritten, again, for notational simplicity,

$n_{T D}=\lambda^{2} \cdot \frac{1}{2} \cdot \varepsilon_{T D} \cdot\left(\chi_{\min }-1\right)^{2} \cdot\left(\frac{\chi_{\min }}{\alpha}\right)^{\frac{2}{\alpha-1}} \cdot\left(\frac{L+L^{*}}{m}\right)^{2} \quad ; \quad \varepsilon_{T D}<1$

with an entirely analogous expression holding for $n_{T D}^{*}$. Now $\varepsilon_{T D}$ is analogous to $\varepsilon_{D}$ from (16) or (17) above, so that $\sqrt{\varepsilon_{T D}}=1-\lambda^{*} \cdot f\left(n_{T D} *\right)$.

The corresponding growth rate will be

$$
g_{T D}=\left(\lambda \cdot \sqrt{2 \cdot n_{T D}}+\lambda^{*} \cdot \sqrt{2 \cdot n_{T D}^{*}}-\lambda \cdot \sqrt{2 \cdot n_{T D}} \cdot \lambda^{*} \cdot \sqrt{2 \cdot n_{T D}^{*}}\right) \cdot \ln \gamma
$$

Next, compare $n_{D}$ and $\mathrm{n}_{T D}$, respectively the equilibrium allocation of resources to R\&D under "free and instantaneous flow of ideas" (or "duplication without trade") and the corresponding allocation when we add trade in intermediate goods to the picture. From (16) and (28), and using the same notation as in (20) or (21), comes

$$
n_{D}=\left(1-p_{D}^{*}\right)^{2} \cdot \lambda^{2} \cdot \frac{1}{2} \cdot(\chi-1)^{2} \cdot\left(\frac{\chi}{\alpha}\right)^{\frac{2}{\alpha-1}} \cdot\left(\frac{L}{m}\right)^{2},
$$

and

$$
n_{T D}=\left(1-p_{T D}^{*}\right)^{2} \cdot \lambda^{2} \cdot \frac{1}{2} \cdot\left(\chi_{\min }-1\right)^{2} \cdot\left(\frac{\chi_{\min }}{\alpha}\right)^{\frac{2}{\alpha-1}} \cdot\left(\frac{L+L^{*}}{m}\right)^{2}
$$


where the subscript "TD" stands for "trade and duplication". On the right side of each expression above, the first term is of order $<1$, as a probability, and then raised to 2 , so it can be ignored. Assuming that both $L$ and $L^{*}$ are equal or bigger than 1 , trade integration will result in a bigger allocation of resources to R\&D and therefore in faster growth as long as the positive "market size effect" (an innovator selling to the world market instead of to the local only) outweighs the negative effect from increased competition (an innovator having to establish a limiting price according to the world's most competitive fringe, that is, according to the lowest level of IPRs). ${ }^{16}$

\section{FINANCIAL MARKET INTEGRATION}

To begin with, we state the problem of allocating resources to R\&D in an integrated financial market where: the research activity is supported not by retained profits at the firms level but by individual savings in exchange for shares of potential innovative firms; simultaneous innovations are bound to happen whenever there exist two or more firms targeting an intermediate good to be quality improved; although it is not possible to prevent Bertrand competition driving profits to zero after simultaneous innovations happen, the financial market is capable of supporting/ implementing any number of potential innovators per good so as to maximize the total return to shares; investors maximize expected returns; there is symmetry in intermediate goods' profitability.

Maximizing the probability that an innovation occurs in a certain industry involves two simultaneous choices: of the number of identical firms within the industry; of the total amount of resources (units of final good) allocated to that industry. If in equilibrium two industries, say $i$ and $j$, present R\&D activity, then it must be the case that

$$
\frac{\partial P_{I}}{\partial N_{I}}=\frac{\partial P_{J}}{\partial N_{J}}, \quad \forall i \text { and } j
$$

where $I \equiv$ the set of potential innovators in industry $i$;

16 We suppose that the binding condition in setting a mark-up is the imitation cost given by the level of IPRs and not the elasticity of substitution among intermediate goods. If the mark-up according to the elasticity of substitution were smaller than that according to the minimal imitation cost, then growth under trade integration would be unambiguously bigger. This artifice of mark-ups given by imitation costs and not elasticities of substitution is employed for example in Acemoglu, Aghion and Zilibotti (2003), presumably because it makes growth performance liable to depend on policies which affect the degree of competition/IPRs. 
$N_{I}=\sum_{i \in I} n_{i}=\#(I) \cdot n_{i} \equiv$ the number of final good's units allocated to innovation in industry $i$;

$$
\begin{aligned}
& P_{I}=\sum_{i \in I} p_{i e} \\
& p_{i e}=p_{i}\left(n_{i}\right)-\prod_{k \in\{i\} \cap \wp(I)} p_{k}\left(n_{k}\right) \equiv
\end{aligned}
$$

$\equiv$ the probability that an innovation occurs exclusively at firm $i$ within industry $I$, when firms in $I$ carry on independent research efforts, so that the probability of intersections or simultaneous innovations is given by the product of individual probabilities $p_{i}\left(n_{i}\right)$, which in turn are functions only of the amount of resources employed at firm level, displaying decreasing returns $\left(p_{i} "\left(n_{i}\right)<0\right)$.

Condition (30) presupposes that given the optimal number of firms inside each industry, functions such as $P_{I}$ display decreasing returns in $N_{I}$, so that there is interindustries diversification in $\mathrm{R} \& \mathrm{D}$. The summation of $N s$ over industries must, in equilibrium, equate total savings. Expressions in (31) reveal a trade-off between exploring decreasing returns at firms level (what would recommend scattering resources through many firms within an industry) and incurring in duplication (what happens on a 2 per 2 basis when there are 2 firms in an industry, on combinations of 2 per 2 and 3 per 3 basis when there are 3 firms, and so on) ${ }^{17}$. Under Aghion and Howitt's (2005) functional form $p_{i}\left(n_{i}\right)=\lambda \cdot \sqrt{2 n_{i}}$, the constraint that investment in R\&D is liable to "lower bound indivisibilities", namely that $n_{i} \geq(\sqrt{2}-1) / \lambda$, ensures that, whatever is $N_{I}, P_{I}$ displays decreasing returns in \#( $\left.I\right)$, the number of firms in $I$, so that in an integrated financial market there will be only one firm being financed to innovate on an intermediate industry. Another way to guarantee this same result is to assume, in general, an upper limit to the number of firms that can, in a given country, target the same good to be innovated and that accumulation has been going on for time enough to make the amount of resources (units of final good) allocated to R\&D in each good big.

Returning to our international context, when besides free flows of ideas, trade in intermediate goods and an internationally integrated market for R\&D financing

17 It is interesting to notice that in situations in which it pays off to run many small projects, maximisation of returns to R\&D depend on non cummulativeness of knowledge. If knowledge is cummulative so that for example only the last firm which innovated on a certain good can perform the next quality jump, of course this firm has a stake in not making this knowledge available in the financial market. 
there is also licensing (that is, R\&D located in one country and intermediate goods production in another country), only the most effectual innovation technologies, as parameterised by $\lambda$ in expression (3) above, will be employed. ${ }^{18}$ The allocation of resources to $\mathrm{R} \& \mathrm{D}$ will be given by

$n_{F}=\left[\max \left(\lambda, \lambda^{*}\right)\right]^{2} \cdot \frac{1}{2} \cdot\left[\chi_{\min }-1\right]^{2} \cdot\left[\frac{\chi_{\min }}{\alpha}\right]^{\frac{2}{\alpha-1}} \cdot\left(\frac{L+L^{*}}{m}\right)^{2}$

where the subscript $F$ stands for "financial integration"

The corresponding common growth rate will be

$g_{F}=\left\{\max \left(\lambda, \lambda^{*}\right) \cdot f\left(n_{F}\right)\right\} \ln \gamma=\left\{\left[\max \left(\lambda, \lambda^{*}\right)\right]^{2} \cdot\left[\chi_{\min }-1\right] \cdot\left[\frac{\chi_{\min }}{\alpha}\right]^{\frac{1}{\alpha-1}} \cdot\left(\frac{L+L^{*}}{m}\right)\right\} \cdot \ln \gamma$

From (29), recall that

$g_{T D}=\left\{\lambda \cdot f\left(n_{T D}\right)+\lambda^{*} \cdot f\left(n_{T D}^{*}\right)-\lambda \cdot f\left(n_{T D}\right) \cdot \lambda^{*} \cdot f\left(n_{T D}^{*}\right)\right\} \ln \gamma$

and

$$
\begin{aligned}
& \lambda \cdot f\left(n_{T D}\right)=\lambda^{2} \cdot\left(\chi_{\min }-1\right) \cdot\left(\frac{\chi_{\min }}{\alpha}\right)^{\frac{1}{\alpha-1}} \cdot \frac{L+L^{*}}{m} \cdot \sqrt{\varepsilon_{T D}} \\
& \lambda^{*} \cdot f\left(n_{T D}\right)=\lambda^{* 2} \cdot\left(\chi_{\min }-1\right) \cdot\left(\frac{\chi_{\min }}{\alpha}\right)^{\frac{1}{\alpha-1}} \cdot \frac{L+L^{*}}{m} \cdot \sqrt{\varepsilon_{T D}^{*}}
\end{aligned}
$$

When compared to $g_{T D}$ given by (29), $g_{F}$ given by (33) represents a more efficient outcome of a laissez faire world economy in the sense that, given a world aggregate allocation $n+n *$ of resources to $\mathrm{R} \& \mathrm{D}$, there is no loss due to duplication - to make an analogy, one may say that the introduction of financial integration has a positive "total factor productivity effect" on research. While, through comparing (32) and (28) where there appears terms like $\varepsilon_{T D}$, we see that the absence of financial integration has also a negative effect on the allocated amount of resources to innovation. ${ }^{19}$ However, for perfectly plausible values of the parameters and of $\varepsilon_{T D}$ and $\varepsilon_{T D}^{*}$

18 See for example Taylor (1994, p. 365): one of the consequences of the absence of international financial capital mobility is the employment of "less than best techniques".

19 We make this analogy bearing in mind Benhabib and Spiegel's (2000) decomposition of the effect of financial development on GNP growth in "total factor productivity" and "factor accumulation" (allo- 
it may be the case that $g_{T D}>g_{F}$, reflecting the well known fact that duplication and patent races lead to overinvestment in R\&D. ${ }^{20}$ In our setup, however, it may also be the case that $g_{T D}<g_{F}$, when countries are already innovating too much and

$$
\max \left(\sqrt{\varepsilon_{T D}}, \sqrt{\varepsilon_{T D}^{*}}\right)=\max \left(\left(1-p_{T D}^{*}\right),\left(1-p_{T D}\right)\right)<1 / 2 \text { or } p_{T D}+p_{T D}^{*}>1
$$

where, as in (21) above, $p_{T D}$ denotes the probability that an innovation is independently made at the home country in the context of absence of financial integration.

This latter possibility arises here because we don't assume, like Jones and Williams (1999) that there is a wedge between "physical" productivity of R\&D as perceived by atomistic innovators and as perceived from the society's standpoint. ${ }^{21}$ In other words, here innovators make their allocation decisions fully incorporating the possibility of total loss due to duplication and free flows of ideas.

Although financial market integration as expressed by $g_{F}$ above promotes efficiency and removes the overinvestment-bound distortion typical of patent races, there still remains, of course, the distortion labelled "creative destruction" by Aghion and Howitt (1992), already commented at the end of section 2 above: From a firm's point of view, and always taking the final good as nmmeraire, the return to a successful innovation is

$$
\pi_{t}=(\chi-1) \cdot\left(\frac{\chi}{\alpha}\right)^{\frac{1}{\alpha-1}} \cdot A_{t} \cdot \frac{L+L^{*}}{m}
$$

While for society the variation in final good's production brought about by an innovation, other things being constant, is

cation) effects. Of course, our negative allocation effect only happens because innovative agents are rational and foresee potential duplication of R\&D efforts in the absence of financial integration.

20 Meaningfully, Jones and Williamson (1999) call duplication "negative congestion externality".

21 In Jones and Williamson (1999) there are constant returns to R\&D from firms' standpoint and decreasing returns from society's standpoint. In Barro and Sala-i-Martin's (1990) learning by doing model with spillovers the case is the opposite: decreasing returns to capital accumulation from the private point of view and constant from the society's. In our setup, given the functional form $f(n)=\sqrt{2 \cdot n}$, there are (equally) decreasing returns from either standpoints. 


$$
\Delta y_{t}+\Delta y_{t}^{*}=(1-\alpha) \cdot\left(\frac{\chi}{\alpha}\right)^{\frac{\alpha}{\alpha-1}} \cdot A_{t} \cdot(\gamma-1) \cdot \frac{L+L^{*}}{m}
$$

since

$$
\frac{\partial y_{t}}{\partial A_{t}}=(1-\alpha) \cdot A_{t}^{-\alpha} \cdot x_{t}^{\alpha} \cdot\left(\frac{L}{m}\right)^{1-\alpha}, \quad \Delta A_{t}=(\gamma-1) \cdot A_{t}
$$

and by (8), (9) and (10) $x_{t}=\left(\frac{\chi}{\alpha}\right)^{\frac{1}{\alpha-1}} \cdot A_{t} \cdot \frac{L}{m}$

When $\chi$ is big, so that monopoly rents are high, and $\alpha$ is big, meaning by (l) that the technology level doesn't matter much, the private return to innovation is higher than the social one. In particular, the term $(\gamma-1)$ in (37) reveals that for society what counts is the productivity improvement, not rents transfers.

A final remark: the international pattern of specialization in $\mathrm{R} \& \mathrm{D}$ promoted by financial integration is completely arbitrary apart from the requirement that only one firm in the world be targeting each intermediate good to be quality-innovated. In the absence of any comparative advantage either in research or in production, there is no way to pin down which "type" of good is bound to be innovated by each country. Even more counterintuitive, each country's R\&D investment may fall on wildly disconnected sets, since there are no increasing returns to concentrate research activity in "clusters" of intermediate goods. A nice alternative to this picture, rendering a clearly cut and homogeneous pattern of specialization in R\&D is to assume intersectoral knowledge spillovers such that, for a continuum of goods, an independent innovation on intermediate good $i$ happens with probability

$$
p(i)=\lambda \cdot n_{i}^{\delta} \cdot\left[\int_{i-\theta}^{i+\theta} n_{j}^{\beta} \cdot d j\right]^{1-\delta-\sigma}
$$

where

$$
0<\delta<1 \text { and } 0<\beta<1
$$

$\theta$ stands for the measure of the "cluster" of intermediate goods in which knowledge spillovers operate;

$\sigma$ merely controls for less than 1 homogeneity degree 
Under (38) and financial integration, potential innovators lying inside relatively more "populated" clusters will receive more resources, that being enough to "coordinate" them. Notice, however, that the presence of positive spillovers entails a further coordination problem: there may be multiple symmetric Nash equilibria $n_{i}$ $\left(n_{j \neq i}\right)$ and inefficient allocations in which the optimal use of resources to innovation on industry $i$ is determined given the other industries' investment levels, while it would pay off increasing investment in $i$ if those levels were bigger, exactly as in Cooper and John (1988). ${ }^{22}$

\section{CONCLUSIONS}

Summarizing the results we got: When compared to a situation where a country is "isolated", integration as free flows of ideas is likely to increase the growth rate, even if the amount of resources each country allocates to innovation on each good falls. When compared to this latter situation, integration via free trade of goods is likely to increase the growth rate through the "market size effect", provided there is no trading partner with too low IPRs. Bringing "financial market integration" into the picture has two different effects on the growth rate: an unambiguously positive one through the selection of most efficient innovation technologies; an ambiguous one through eliminating redundancy: if the R\&D activity was already too "congested" with duplication under free flows of ideas plus trade integration then the growth rate will increase; otherwise, it will be smaller under financial integration, but this will be in general welfare improving since we might expect an overall excess of investment to exist in the presence of patent races.

\section{REFERENCES}

ACEMOGLU, D.; AGHION, P.; ZILIBOTTI, F. Distance to frontier, selection and economic growth. (revision 2003)

AGHION, P.; HOWITT, P. A model of growth through creative destruction. Econometrica, v. 60, n. 2, March 1992.

22 Notice also that this idea of intersectoral spillovers as a means of generating a well-behaved pattern of international specialisation in trade and $\mathrm{R} \& \mathrm{D}$ is quite different from the one suggested by Aghion and Howitt $(2005$, p. 7). There, an innovation in sector i, say, will embody the state-of-the-art technology or maximum productivity level across all sectors. As they put it, "The idea is that if a sector has been unlucky for a long time, while the rest of the economy has progressed, the technological progress elsewhere spills over into the innovation in this sector, resulting in a larger step than if innovation had occurred many years ago". 
. Growth with Quality-Improving Innovations: an Integrated Framework - in AGHION, P.; DURLAUF, Steven (ed.). Handbook of economic growth. Elsevier, 2005.

BARRO, R.; SALA-I-MARTIN, X. Public finance in models of economic growth. NBER Working Paper no 3362, 1990.

BENHABIB, J.; SPIEGEL, M. The role of financial development in growth and investment. Journal of Economic Growth, 5, 2000.

COOPER, R.; JOHN, A. Coordinating coordination failures in keynesian models. Quarterly Journal of Economics, v. CIII, 1988.

DASGUPTA, P.; MASKIN, E. The simple economics of research portfolios. The Economic Journal, September 1987.

GANCIA, G. Globalization, divergence and stagnation. CREI Universitat Pompeu Fabra, 2003.

GROSSMAN, G.; HELPMAN, E. Innovation and Growth in the Global Economy. MIT Press, 1991.

HOWITT, P. Endogenous growth and cross-country income differences. American Economic Review, 90, 2000.

JONES, C. R\&D-Based Models of Economic Growth. Journal of Political Economy, V. 103, n. 4, 1995.

; WILLIAMS, J. To much of a good thing? The economics of investment in RéD. Stanford University Economics, 1999 (Working Paper $n^{\circ} 99$ - 015).

LA MANNA, M.; MACLEOD, R.; MEZA, D. The case for permissive patents. European Economic Review, 33, 1989.

RIVERA-BATIZ, L.; ROMER, P. Economic integration and endogenous growth. Quarterly Journal of Economics, 1991.

STOKEY, N. R\&D and Economic Growth. The Review of Economic Studies, v. 62, n. 3, Jul.1995.

TAYLOR, S. M. Trips, trade and growth. International Economic Review, v. 35, 1994. 